\title{
Работа нечеловеческого
}

\section{Реза НегАРЕСТАНИ}

Руководитель, программа по критической философии, Новый центр исследований и практики (Сиэтл, США). Aдpec: 4739 University Way NE \#1320, WA 98105 Seattle, USA. E-mail: reza.negarestani@thenewcentre.org.

Ключевые слова: ингуманизм; гуманизм; нечеловеческое; обязательство; пространство резонов; пересмотр; человек.

Статья посвящена обоснованию проекта ингуманизма как практического развития просвещенного гуманизма. Автор последовательно отстраивает свой проект от антигуманизма, современного гуманизма и так называемого китч-марксизма. Отталкиваясь от тезиса о понятии человека как эпистемологическом, ингуманизм непрерывно подвергает пересмотру то, что значит быть человеком. При этом устраняются его предположительно самоочевидные характеристики и сохраняются надежные инварианты. Поэтому ингуманизм - это требование конструирования: он требует, чтобы мы определили, что значит быть человеком, рассматривая того как конструируемую и плодотворную гипотезу, как пространство для навигации и вмешательства и учитывая сегодняшний день. Понятие человека - это обязательство в отношении человечества. Взять обязательство - значит спрашивать «что еще?», быть внимательным к тому, какие еще обязательства оно влечет за собой и как эти логически следующие обязательства требуют новых способов действия и понимания, новых способностей и особых поступков. Следова- тельно, чтобы понять и взять на себя обязательство перед человечеством, необходимо занять позицию конструирования и пересмотра по отношению к человеку, то есть начать практиковать ингуманизм.

Условие такого пересмотра-автономия разума (sapience), функционально отличающегося от чувственности (sentience) способностью участвовать в дискурсивных практиках, обмениваться резонами. Без этой способности бытие человеком - лишь биологический факт. И это предполагает императив создания, а не только потребления норм. При этом сама программа ревизии разума, которую активирует ингуманизм, автономна: человек не контролирует ее. Ингуманизм - это работа рациональной агентности над человеком, поэтому, чтобы быть свободным, необходимо быть рабом разума. Перефразируя Мишеля Фуко, автор заявляет, что каждый автопортрет человека смывается ревизионной властью разума, уступая место более утонченным портретам, в которых так мало канонических черт, что следовало бы задаться вопросом: стоит ли, оправданно ли называть остаток «человеком»? 


\section{Часть 1. Человек}

И

НГУМАНИЗМ - это расширенное практическое развитие гуманизма; он рождается из внимательного следования проекту просвещенного гуманизма. Будучи мировой волной, стирающей автопортрет человека, нарисованный на песке, ингуманизм - это вектор пересмотра. Он безжалостно пересматривает, что значит быть человеком, устраняя его предположительно самоочевидные характеристики и сохраняя надежные инварианты. В то же время ингуманизм - это требование конструирования: он требует, чтобы мы определили, что значит быть человеком, рассматривая его как конструируемую и плодотворную гипотезу, как пространство для навигации и вмешательства ${ }^{1}$.

Ингуманизм твердо противостоит любой парадигме, которая стремится принизить человечество, сталкивая его с его же конечностью или с великим Внешним. Работа ингуманизма состоит в том числе в том, чтобы очищать значение человеческого от всех предопределенных смыслов или сущностей, привнесенных из теологии. Тем самым он делает возможным признание значения человеческого без всякого преклонения перед человеком, которое возникает, когда это значение приписывается какой-нибудь тео-

Перевод с английского Светланы Вербицкой по изданию: ( ) Negarestani $R$. The Labor of the Inhuman // \#ACCELERATE: The Accelerationist Reader/ R. Mackay, A. Avanessian (eds). Falmouth: Urbanomic, 2014. P. 425-466. Публикуется с любезного разрешения автора.

1. На протяжении этого текста мы подчеркиваем, что человек-это единичное универсальное, которое придает смысл своему способу существования, осваивая коллективизирующие или универсализирующие процессы. Человек является человеком не просто потому, что он - биологический вид, а потому, что он - родовой субъект или обыватель перед лицом того, что выявляет его единичность и универсальность. Соответственно, человек, как указывает Жан-Поль Сартр, универсален в силу единичной универсальности истории человечества и единичен в силу универсализирующей единичности его проектов (см.: Сартр Ж.-П. Идиот в семье. Гюстав Флобер с 1821 до 1857 года. СПб.: Алетейя, 1998. С. 7. - Прим. ред.). 
логической инстанции (Богу, невыразимой общности, фундирующей аксиоме и т. д.) $)^{2}$.

Если заменить перемешанное с чем-то другим и хвалебное значение человека реальным содержанием, минималистичным, но функционально последовательным, то унизительное кредо антигуманизма, опирающегося на укорененное в теологии смешение значения и преклонения, теряет свою дисквалифицирующую силу. Антигуманизм неспособен сохранить свою релевантность, не обращаясь к привнесенному из теологии понятию кризиса, и безуспешно пытается выделить значение человека путем распутывания патологического смешения реальной важности человека и преклонения перед ним. Именно поэтому антигуманизм оказывается в той самой теологической лодке, которую так хочет потопить.

Антигуманизму не удается выделить это значение в соответствии с физикой, которая его утверждает, а не метафизикой, которая его раздувает, поэтому он находит только один способ преодолеть предполагаемый кризис значения - принять культурную разнородность ложных альтернатив (растущее количество пости коммунитарных отступлений в качестве так называемых альтернатив тотальности и проч.). Эти альтернативы коренятся в изначальном, так никогда и не разрешенном смешении, они постоянно колеблются между противоположными крайностями - инфляционной и дефляционной, заколдовывающей и расколдовывающей. Тем самым они создают иллюзию свободы, которая душит любые универсалистские амбиции и препятствует методологическому сотрудничеству, необходимому для определения и выполнения общей задачи - вырваться из трясины, в которой увязла вся планета.

Словом, избыток ложных альтернатив, предлагаемых под вывеской либеральной свободы, в итоге приводит к дефициту настоящих альтернатив и создает для мысли и действия аксиому, что таких альтернатив на самом деле и нет. В этом эссе отстаивается тезис, что универсальность и коллективизм нельзя помыслить и тем более достигнуть через консенсус или распрю культурных тропов; это возможно, только если будет прекращено и выкорче-

2. В особенности элегантный и резкий аргумент в защиту человеческого значения как обусловленного нейробиологической ситуацией субъективности, а не Богом или религией был предложен Майклом Феррером. Он весьма плодотворно демонстрирует, что такая просвещенная и избегающая смешения ревизия значения человека подрывает как теологически инспирированное преклонение перед человеком, так и его преуменьшение, или дефляция, отстаиваемое многими течениями в рамках проекта по расколдовыванию мира и его спекулятивными ответвлениями. 
вано то, что порождает экономию ложных альтернатив, и если будет приведено в действие и полностью разработано то, в чем состоит настоящее значение человека. Как будет показано, истина значения человека - не в смысле изначального значения или права, данного от рождения, а в смысле труда, который состоит в расширенной разработке того, что значит быть человеком, посредством ряда совершенствуемых специальных действий, - является строго нечеловеческой (inhuman).

Ингуманизм ретроактивно сдерживает антигуманизм, поскольку понимает человечность исторически - в самом широком физико-биологическом и социально-экономическом смысле слова «история», - как неизбежный путь к самому себе.

Но что такое гуманизм? Какое специфическое обязательство подразумевает бытие человеком и каким образом его полная практическая разработка равнозначна ингуманизму? Другими словами, что именно в человеке, когда оно разработано в плане своих правомочий (entitlements) и последствий, формирует нечеловеческое (inhuman)? Дабы ответить на эти вопросы, нужно сперва определиться с тем, что значит быть человеком и какое именно обязательство подразумевается этим «быть человеком». Затем мы должны будем проанализировать структуру этого обязательства, чтобы понять, как из взятия его на себя - в смысле его практикования - следует ингуманизм.

\section{1. Обязательство как расширенная и мультимодальная разработка}

Обязательство имеет смысл исключительно в силу своего прагматического содержания (значения как употребления) и своего требования принять корректируюшую установку, то есть позицию, стремящуюся разработать содержание обязательства, а затем обновить это обязательство в соответствии с ответвлениями или второстепенными обязательствами, выявленными в процессе разработки. Словом, обязательство - будь оно утверждающее, инференциальное (выводное), практическое или когнитивное - не может быть ни проверено, ни должным образом принято без процесса его обновления и анализа его последствий с помощью всего спектра мультимодальных практик. Таким образом, гуманизм - это и в самом деле обязательство по отношению к человечеству, но, чтобы понять это, необходимо исследовать, что такое обязательство, что такое человек и что их сочетание влечет за собой. 
Это означает, что анализ структуры и законов процесса принятия обязательства, а также значения того, что значит быть человеком в прагматическом смысле (то есть не путем обращения к необходимой концепции значения, скрытой в природе, или к некой предопределенной идее человека), является необходимым первичным шагом, предваряющим вхождение в область производства предписаний (социальных, политических или этических). Для начала необходимо прояснить, что требуется для создания предписания или что надо делать, чтобы считаться предписывающим, связывающим и пересматривающим обязательство или обязанность. Но также надо признать, что предписание должно соответствовать ряду описаний, которые на всех этапах должны быть синхронизованы с системой современного знания, создающей и изменяющей эти описания. Говоря коротко, описание без предписания - это первый шаг к сдаче обязательства, а предписание без описания - обычный каприз.

Таким образом, это попытка понять, как организовано предписание или что влечет за собой создание предписания человеком и для человека. Без такого понимания не получится адекватно отличить прескриптивные нормы от норм дескриптивных (в таком случае никаких предписаний не может быть) и не получится сконструировать правильные предписания, так как они выродятся в бесполезные предписания без описаний.

Описание содержания человека невозможно, пока мы не разработаем его в контексте использования и практик; в свою очередь, сама эта разработка невозможна, пока мы не следуем минимально предписывающим законам принятия обязательства, вывода и суждения. Описание человека без обращения к основополагающим описаниям или некоторого априорного доступа к средствам описания уже является минимально, но функционально гегемонным предписывающим проектом. Такой проект верен обязательствам спецификации и разработки значения бытия человеком через характеристики и условия его применения. Будучи «осложнен долженствованиями» (fraught with oughts, по выражению Уилфрида Селларса), гуманизм не может считаться утверждением о человеке, которое можно единожды заявить и впоследствии превратить в основание или аксиому и на этом закончить. Ингуманизм - обозначение недопустимости такого однократного заявления. Это символ того, что вопрос невозможно разрешить раз и навсегда.

Быть человеком - это след различия между двумя отношениями. С одной стороны, отношением между сознательностью (mindedness) и поведением, опосредованным вмешательством дис- 
курсивной интенциональности, а с другой стороны, отношением между чувственным рассудком и поведением в отсутствие такого посредничества. Это различие между чувственностью (sentience) как преимущественно биологической и природной категорией и разумом (sapience) как рациональным (не путать с логическим) субъектом. Последний является нормативным обозначением, которое характеризуется правомочиями и сопутствующими обязательствами. Важно отметить, что различие между чувственностью и разумностью функциональное, а не структурное, поэтому оно полностью исторично и открыто для натурализации и в то же время отличается специфической функциональной организацией, обновляемым набором способностей и обязательств, когнитивными и практическими требованиями. Отношение между чувственностью и разумностью можно понять как не везде дифферениируемыци континуум. Такая сложная непрерывность перехода между ними допускает натурализацию нормативных обязательств на уровне разумности, то есть их объяснение через натуралистические причины, однако при этом она не разрешает распространять на чувственность и далее концептуальные и описательные средства (такие как конкретный уровень сознательности, обязательств и, соответственно, нормативных правомочий).

Граница рационального проходит между способностью признать закон и простой связанностью законом, между пониманием и всего лишь надежной реакцией на стимулы. Она заключается в разнице между устойчивой коммуникацией посредством понятий (ставшей возможной благодаря коллективному пространству языка и символических форм) и хаотически неустойчивыми или недолговечными типами реакции или коммуникации (такими как комплексные реакции, запускаемые исключительно биологическими состояниями и органическими потребностями, или групповые зовы и сигналы тревоги у социальных животных). Без такой стабилизации коммуникации с помощью понятий и умозаключений, используемых в понимании (conception), становятся невозможными как культурная эволюция, так и понятийное накопление и понятийное совершенствование, необходимые для эволюции знания как совместного предприятия ${ }^{3}$.

3. «Эпистемическая динамика, основанная на взаимодействии множества личностей, работает с пользой, только если гарантирована устойчивость совместного знания и входного подключения этого знания (его „реализм“). В противном случае система знания, хотя и будучи когнитивно возможной, не может быть ни реализована социально, ни разработана в культурном плане. Поскольку в сложных социальных сетях дар- 
В конечном счете необходимое содержание, равно как и реальная возможность человека, опирается на способность разума - как функционально отличающуюся от чувственности - осуществлять вывод и приближаться к неканонической истине, включаясь в деонтическую игру требования и предъявления резонов. Разум является игрой лишь в том смысле, что предполагает устойчивые к ошибкам (error-tolerant) и правилосообразные практики, которые ведутся в отсутствие арбитра и в которых постоянно сопоставляются, оцениваются и калибруются принятие-за-истинное (taking-as-true) посредством мышления (знак верующего) и воплощение (makingtrue) посредством деятельности (знак агента). Это динамическая обратная связь, в которой расширение одного фронтира - принятие-за-истинное или воплощение, понимание или действие- обеспечивает другой новыми альтернативами и возможностями для диверсификации его пространства и сдвигания его границ в соответствии с собственными спецификациями и требованиями.

\section{2. Дискурсивное и конструируемое «мы»}

Способность делать выводы и способность приближаться к истине (истине как осмыслению принятия-за-истинное и воплощения как отдельно друг от друга, так и вместе) объединяет способность осуществлять дискурсивные практики, как это описывает прагматизм: способность (1) развернуть словарь, (2) использовать словарь для точного определения группы способностей и практик, (3) раскрыть группу способностей-или-практик с помощью другой группы способностей-или-практик и (4) использовать один словарь для характеристики другого ${ }^{4}$.

Дискурсивные практики лежат в основе игры требования и предъявления резонов и очерчивания пространства разума, понимаемого как ландшафт для навигации, а не как априорно имеющийся доступ к сформулированным нормам. Этот инференциа-

винистский отбор действует на уровне социальных сущностей (которые или выживают, или исчезают), только виды, решившие сформулированную выше проблему, могут пользоваться выгодами более высокого уровня познания. Отсюда вопрос: как язык - или же другие символические формы - способствует эволюции социальной осведомленности, социального сознания, социального познания?» (Wildgen W. The Evolution of Human Language: Scenarios, Principles, and Cultural Dynamics. Philadelphia: John Benjamins, 2004. P. 40).

4. См.: Brandom R. Between Saying and Doing: Towards an Analytic Pragmatism. Oxford: Oxford University Press, 2008. 
листский, процедурный и некодифицированный подход к разуму рассматривает его как расширяющийся инструментарий практик, управляемых правилами, но вместе с тем устойчивых к ошибкам и открытых для пересмотра. Именно способность участвовать в дискурсивных практиках функционально отличает разум (sapience) от чувственности (sentience). Без этой способности «быть человеком» - лишь биологический факт, сам по себе не ведущий ни к какой пропозициональной содержательности, которая бы требовала особой формы поведения, ценностной атрибуции и оценки. Не признав этот ключевой аспект, в разговоре о человеческой истории мы рискуем свести социальную конструкцию к биологической детерминации и лишить историю всякой возможности вмешательства и переориентации.

Другими словами, без возможности вступить в пространство разума посредством дискурсивных практик бытие человеком теряет всякую связь с релевантным отношением между практикой и содержанием. Если действие сводится к «просто делать что-то», то коллективность никогда не сможет быть методологической или выражаться исходя из синтеза разных способностей представлять общую цель и достигать ее, а принятие обязательств через соединение действия и понимания оказывается несостоятельным. С тем же успехом мы можем заменить слово «человек» на что угодно, чтобы построить вещно-ориентированную философию и нечеловеческую этику, в которых «быть вещью» просто гарантирует хорошее отношение друг к другу - или к овощам, раз уж на то пошло.

Если дискурсивные практики, размечающие смысловое пространство разума, недооцениваются или вовсе игнорируются, то все скатывается либо к индивидуальному, либо к ноуменальной инаковости, в которой можно без труда насаждать бессодержательную множественность, лишенную каких-либо требований и обязательств. Дискурсивные практики, укорененные в употреблении языка и пользовании инструментами, порождают лишенное приватного, но тем не менее стабилизирующее и контекстуализирующее пространство, в котором формируются настоящие коллективизирующие процессы. Именно в этом пространстве разума содержится функциональное ядро подлинной коллективности - основанного на сотрудничестве проекта практической свободы, зовущегося «мы». Его границы не только являются предметом договоренностей, они также конструируются и носят синтетический характер.

Следует помнить, что «мы» - это способ бытия, а способ бытия - это не онтологическая данность и не область, сводящаяся к набору фундаментальных категорий или фиксированных опи- 
саний. Это поведение, особое действие, которое как таковое приобретает форму, когда делается видимым для других. Препятствуя такому явному и дискурсивно мобилизуемому «мы», содержание «быть человеком» никогда не переводится в «обязательство в отношении человека/человечества». Укрепляя «мы», дискурсивные практики организуют обязательства как разветвляющиеся траектории между совместными высказываниями и делами; они реализуют пространство, в котором самоконструирование или обширная практическая разработка человечества является проектом, основанным на сотрудничестве.

Брать обязательство по отношению к чему-то означает колебаться между двумя полями: с одной стороны, делать что-то, чтобы считаться высказывающими это что-то, с другой - высказывать что-то конкретное, чтобы выражать и характеризовать это делаемое.

Именно это движение вперед и назад, петля обратной связи между двумя полями утверждений и действий, определяет разумность в противовес чувственности ${ }^{5}$. Взять обязательство - значит спрашивать «что еще», быть внимательным к тому, какие еще обязательства оно влечет за собой и как такие обязательства требуют новых способов действия и понимания, новых способностей и особых поступков, которые не являются просто взаимозаменяемыми со старыми способностями, поскольку продиктованы пересмотренными или более сложными наборами требований и правомочий. Без такого разветвления «что еще» обязательства посредством его практической разработки, без навигации по тому, что Роберт Брэндом называет рациональной системой обязательств ${ }^{6}$, о обязательства нет ни достаточного содержания, ни реальной возможности оценки или развития. Оно становится пустым высказыванием, лишенным содержания или значения, несмотря на самую искреннюю приверженность.

\section{3. Вмешательство как конструирование и пересмотр}

Теперь мы можем превратить аргумент о требованиях, предъявляемых принятием обязательства, в аргумент о требованиях к бытию человеком, сколь скоро гуманизм является системой практи-

5. Необходимо заметить, что разумное также чувственно, однако оно функционально отличается от своего чувственного устройства. Именно это функциональное различие делает чувственность человека отличной от других форм чувственности. Говоря иначе, разумное наделено функциональной способностью перестраивать свою чувственность как устройство.

6. Brandom R. Between Saying and Doing. 
ческих и когнитивных обязательств по отношению к понятию человечества. Этот довод может быть сформулирован следующим образом: чтобы взять на себя обязательство перед человечеством, необходимо подвергнуть содержание человечества критическому изучению. А чтобы критически изучать это содержание, необходимо разработать его скрытые обязательства. Но эта задача выполнима, если только мы выведем предельное следствие из человечества-как-обязательства, задаваясь вопросом, что еще влечет за собой бытие человеком, развертывая другие обязательства и вытекающие из него ветви следствий.

Но так как содержание человечества определяется способностью человека следовать рациональным нормам, а не законам природы (должно вместо есть), понятие следования для человечествакак-обязательства оказывается немонотонным. То есть, когда мы спрашиваем, что влечет за собой бытие человеком, это следование уже не лежит в плоскости причины и ее дифференциального эффекта, как в случае физических природных законов или дедуктивных логических умозаключений. Напротив, оно выражает открытие возможностей (enablement) и абдуктивную немонотонность в смысле изменяемой, опытной и синтетической формы вывода, в котором заключения не следуют напрямую или линейно из его посылок или исходных условий ${ }^{7}$. Так как немонотонность - неустранимое свойство практики и сложной эвристики, определение человека с помощью практической разработки означает, что результат этой разработки не соответствует ожиданиям человека или его образу самого себя. Другими словами, результат абдуктивного вывода, синтетически преобразующего параметры, бу-

7. Абдуктивный вывод, или абдукция, впервые был обозначен Чарльзом Сандерсом Пирсом в качестве формы творческого предположения или гипотетического вывода, которая использует мультимодальные и синтетические формы рассуждения для динамического расширения своих способностей. Есть разные типы абдуктивного вывода, но все они немонотонные, динамические и неформальные. Также они включают в себя конструирование и преобразование, использование сложных эвристических стратегий и необъяснительные формы порождения гипотез. Абдуктивное рассуждение - это важный элемент логики открытия, эпистемического контактирования с аномалиями и динамическими системами, часть творческого экспериментирования, действия и понимания в ситуациях, когда и материальные ресурсы, и эпистемические сигналы ограничены или должны быть сведены к минимуму. Обстоятельное исследование абдукции и ее практических и познавательных возможностей см.: Magnani L. Abductive Cognition: The Epistemological and Ego-Cognitive Dimensions of Hypothetical Reasoning. B.: Springer, 2009. 
дучи результатом практики как немонотонной процедуры, будет подвергать радикальному пересмотру наши допущения и ожидания относительно того, что такое «мы» и что из него следует.

Немонотонность и абдуктивность устойчивых социальных практик, формирующих и укрепляющих пространство разума, делают рассуждение и соответствующую установку вмешательства непрерывными процессами. В самом деле, разум как укорененный в социальных практиках необязательно направлен на логическое заключение и не стремится учредить соглашения в рамках субстантивного и квазиинструментального подхода к разуму, предлагаемого философами вроде Юргена Хабермаса ${ }^{8}$. Главная цель разума - поддерживать и усиливать себя. И именно самоактуализация разума совпадает с истиной нечеловеческого. Здесь под разумом нужно понимать не что-то жесткое и неизменяемое, а развивающееся пространство, которое перестраивает себя посредством корректируемых правил, одновременно сохраняющих и смягчающих неведение (ср. с абдуктивной немонотонностью).

Разбор содержания обязательства в отношении человечества и прояснение того, на что еще уполномочивает нас человечество, невозможны, пока мы не разовьем установку вмешательства. Такая установка предполагает одновременную оценку (или потребление) и конструирование (или производство) норм. Только при таком вмешивающемся отношении к понятию человечества мы получаем возможность выделить и разобрать скрытые обязательства бытия человеком. Именно такая установка вмешательства является уполномочивающим вектором, делающим возможными способности, которые в противном случае остались бы скрытыми или считались бы невозможными.

Именно благодаря потреблению и производству норм можно понять содержание обязательства в отношении человечества, то есть оценить и прояснить накладываемые им на нас неявные обязательства. Соответственно, чтобы понять и взять на себя обязательство в отношении человечества, необходимо занять позицию конструирования и пересмотра по отношению к человеку. В этом и заключается упомянутая выше установка вмешательства.

Пересмотр и конструирование человека и составляет определение обязательства в отношении человечества. Без этого постоянного пересмотра и конструирования «обязательство» в «связывании себя обязательством в отношении человечества» не имеет

8. См.: Laden A. S. Reasoning: A Social Picture. Oxford: Oxford University Press, 2012. 
никакого смысла. Но, кроме того, поскольку человечество невозможно определить, не размещая его в пространстве резонов (аргумент разумности), принятие обязательства в отношении человечества равносильно подчинению пересматривающему вектору разума и конструированию человечества в соответствии с автономным подходом к разуму.

Человечество - не просто данность, на фоне которой мы существуем. Это обязательство, в котором переплетаются линии переоценки и конструирования, свойственные принятию обязательства и подчинению разуму. Короче, быть человеком - это борьба. Ее цель - ответить на требования конструирования и пересмотра человека в пространстве резонов.

В этой борьбе в соответствии с функциональной автономностью разума вырабатывается устойчивое к ошибкам поведение - установка вмешательства, целью которой является выявление новых способностей высказываться и действовать. Другими словами, открытие новых фронтиров действия и познания с помощью различных способов конструирования и практик (социальных, технологических...).

\section{4. Китч-марксизм}

Если связывание обязательством в отношении человека - это усилие по конструированию и пересмотру, то сегодняшний гуманизм - это по большей части пустое предприятие, в котором не делается то, о чем заявляется, и не проговаривается то, что делается. Социально-политические философии, пытающиеся защитить достоинство человечества от натиска политико-экономических левиафанов, в конечном счете присоединяются к ним, просто с другой стороны.

Тому же, что заявляет о себе как о современном марксизме, в основном не удается вырабатывать нормы действий и познания из-за отказа признать автономность разума и систематически вкладываться в установку вмешательства (то есть конструирования и пересмотра) по отношению к человеку и нормам, неявно задаваемым социальными практиками. В результате этот современный марксизм вычитает себя из будущего человечества. Только конструируя то, что значит быть человеком, можно создавать нормы обязательства в отношении человечества. И только пересматривая существующие нормы через призму так произведенных норм, можно оценить нормы и, главное, дать оценку тому, что значит быть человеком. Повторюсь, эти нормы следует отличать 
от социальных договоренностей и не путать их с законами природы (это не законы, а концепции законов, поэтому-то они устойчивы к ошибкам и могут подвергаться пересмотру). Производство или конструирование норм стимулирует потребление или оценку норм, что, в свою очередь, ведет к спросу на производство более новых способностей и более сложных нормативных установок.

Невозможно оценивать нормы, не производя их. То же можно сказать и об оценке ситуации человечества, статусе обязательства быть человеком: человечество не может оцениваться ни в каком контексте или ситуации, если по отношению к нему не разработана конструктивная установка вмешательства. Но развивать такую конструктивную установку в отношении человека - значит решительно подвергать пересмотру то, что значит быть человеком.

Посвящение себя проекту милитантной негативности и отказ от стремления развивать по отношению к человеку установку вмешательства и конструирования посредством разнообразных социальных и технологических практик-отличительные признаки сегодняшнего китч-марксизма. Хотя и не весь марксизм следует относить к китч-марксизму (особенно потому, что классовая борьба как главный догмат марксизма является непреложным историческим проектом), заявление «Я - марксист» оказывается чересчур родовым. Это все равно что сказать: «Я - животное». Оно не имеет никакого теоретического или практического смысла.

Любую марксистскую повестку надо оценивать по тому, способна ли она разработать взятые обязательства, поняты ли в ней основные механизмы взятия обязательства и, главное, есть ли в ней программа по глобальному обновлению своих обязательств. Если ценится практическая негативность, а отбрасывается установка вмешательства или конструктивный образ действия, то оценка человечества и его состояний становится фундаментально проблематичной на последующих уровнях.

Без конструктивного вектора проект оценки - критика - превращается во всего лишь потребительское отношение к нормам. Потребление норм без их производства - это реальность сегодняшней марксистской критической теории. На каждое утверждение в ней уже заготовлен набор «критических рефлексов» ${ }^{9}$. Скажем, выдвигают тезис в защиту достоинств лучшего соображения. Ответ китч-марксизма: кто принимает решение? Предлагают использо-

9. Этим термином я обязан Питеру Вулфендейлу. Под критическими рефлексами он подразумевает заготовленные теоретические предубеждения, используемые для перехвата требований мысли во имя критической мысли. 
вать в конструировании структурную и функциональную иерархии. Китч-марксист отвечает: контроль. Говорят: нормативный контроль. Тогда китч-марксист напоминает нам об авторитаризме. Мы говорим: «мы». Китч-марксист автоматом парирует: кто эти «мы»? Эту импульсивную реактивность даже не назвать циничной установкой, ведь в ней нет безжалостности цинизма. Эта механизированная и абсолютно предсказуемая реактивность - истинное выражение консюмеризма норм в отсутствие конкретного обязательства производить какие-либо нормы. Консюмеризм норм - это другое название когнитивного рабства и интеллектуальной лени.

Ответ китч-марксизма человечеству проблематичен и на уровне пересмотра. Перестать производить нормы из-за отказа занять конструктивную позицию по отношению к человеку - в смысле поведения, ведомого функциональной автономией разума, - значит прекратить пересмотр того, что значит быть человеком. Почему? Потому что нормы оцениваются и изменяются новыми нормами, произведенными в разных режимах конструирования, сложных социальных практик и размыкания новых способностей двигаться от слов к делам и обратно. Так как человек отличается тем, что способен участвовать в игре предъявления и требования резонов, конструирование человека должно идти в направлении дальнейшего вычерчивания пространства разума, посредством которого человек отличает себя от нечеловеческого (nonhuman), разумность от чувственности.

Превращая этос конструирования согласно требованиям разума в пафос негативности, китч-марксизм не только кладет конец проекту пересмотра, но и делает ставку на концепцию человечества вне пространства разума, хотя ревизионная сила разума - единственная сила, способная пересматривать и определять человечество. Как только пересмотр прекращается, понимание человечества и влияние на его ситуации теряют всякий смысл, поскольку то, что считается человеком, больше не является нерелевантным ${ }^{10}$. Аналогичным образом, как только образ человечества начинают искать за пределами разума, лишь вопросом времени становятся схлопывание деонтологического различия между разумностью и чувственностью и проявление очевидных признаков иррационализма - легкомыслия, нарциссизма, предрассудков, спекулятивного энтузиазма, социального атавизма и, наконец, тирании.

10. Не секрет, что большая часть современных социально-политических предписаний основывается на концепции человечества, которая не смогла синхронизировать себя с современной наукой или учесть социальные и организационные изменения, обусловленные технологическими силами. 
Поэтому первое, что нужно спрашивать у гуманиста или марксиста: соответствуют ли ваши обязательства сегодняшнему дню? Если ответ - да, то они должны быть подвергнуты деонтическому суду - какой-то версии деонтического ведения счета Роберта Брэндома или деонтического испытания Жан-Ива Жирара, где обязательства могут рассматриваться исходя из их связности, отсутствия порочных кругов и внутренних противоречий, а также их оценки на основе отвода (recusal), а не доказательства несостоятельности (refutation) ${ }^{11}$.

Если обязательство в отношении человечества отождествляется с активным пересмотром и конструированием, то прекращение пересмотра и отказ конструировать характеризуют иррационализм, нацеленный аннулировать то, что значит быть человеком. Именно в этом смысле китч-марксизм является не только теоретической некомпетентностью. С исторической и когнитивной точек зрения это еще и импульс к регрессу от разумности к чувственности.

В этом смысле не будет преувеличением сказать, что в каждой программе китч-марксизма есть зачаток враждебности к человечеству и гуманистическому проекту. Практическая негативность отказывается быть пассивной, но одновременно отказывается делать вклад в систему и развивать систематический подход к аффирмативной установке, «неявно» присутствующей в конструировании системы.

Для гуманизма же характерна аффирмативная установка конструирования. Коль скоро китч-марксизм скрывает в себе отказ от проекта гуманизма и скатывание в регрессивную пассивность, можно сказать, что отказ китч-марксизма и уступать, и строить ставит его в позицию, которая не является ни пассивной, ни гуманистической. В действительности такой подход «ни/ни» как раз и указывает на проект активного антигуманизма, которому на са-

11. Здесь понятие отвода используется как навигационный и процедурный эквивалент отрицания в расширяющейся - или, точнее, разветвляющейся - системе обязательств. Если доказательство несостоятельности мгновенно исключает противоречие, то отвод - это способ действия в сетке обязательств в соответствии с собственными разветвлениями этого обязательства (то есть его толерантностью к пересмотру и обновлению). Подобно судебным разбирательствам, основанным на принятии возражения или отказе в нем, логический отвод разрешает или блокирует навигацию по разветвленному пути обязательства на основе деонтической позиции. Подробнее о различии между доказательством несостоятельности и отводом см.: Girard J.-Y. Geometry of Interaction VI: A Blueprint for Transcendental Syntax//L'Institut de mathématiques de Luminy. 2013. URL: http://iml.univ-mrs.fr/ girard/blueprint.pdf. 
мом деле привержен китч-марксизм, несмотря на его притязания на обязательство в отношении человека. В свете такого антигуманизма, такой враждебности по отношению к следствиям обязательства в отношении человека отождествление программ китчмарксизма с гуманизмом представляется в лучшем случае фарсом, в худшем - критической версией финансовой пирамиды для убежденных гуманистов.

Миссия ингуманизма - соединить преданность гуманизму со сложными способностями и обязательствами, поэтому он оказывается той силой, которая выступает против пораженческой апатии и активного антигуманизма, скрытых в практической негативности модного сегодня китч-марксизма. Ингуманизм, как будет показано ниже, является и расширенной разработкой следствий взятия на себя обязательства по отношению к человечеству, и практической разработкой содержания понятия человека - все благодаря разуму и разумной способности функционально отличать себя и участвовать в дискурсивных социальных практиках.

\section{Часть 2. Нечеловек}

Просвещенный гуманизм - как проект обязательства по отношению к человечеству как переплетения того, что значит быть человеком, и того, что значит принять на себя обязательство, - является рациональным проектом. Рациональным не только потому, что размещает значение человека в пространстве резонов как особый горизонт практик, но, что важнее, еще и потому, что понятие обязательства, к которому он привязан, не может мыслиться или практиковаться как волюнтаристский импульс, свободный от следствий и растущих обязанностей. Вместо этого обязательство понимается как рациональная система для навигации по сопутствующим обязательствам - их следствиям, равно как и их специфическим правомочиям, - которые вытекают из исходного обязательства.

Взаимодействие с рациональной системой обязательств вписывается в навигационную парадигму, в которой следует неотступно разрабатывать ветвящиеся следствия исходного обязательства и ориентироваться среди них, чтобы обязательство имело смысл в качестве принятого. Именно изучение рационального результата принятия обязательства, выявление его далеко идущих последствий и трактовка этих ветвящихся следствий как путей, которые нужно исследовать, и делает из обязательства в отношении человечества навигационный проект. Здесь под навигацией понимается не только обзор ландшафта, границы которого 
не даны. Это еще и упражнение в немонотонных процедурах следования по маршрутам и их построения, приостановки навигационных предубеждений, отбрасывания или разрешения несовместимых обязательств, исследования пространства возможностей и понимания каждого пути как гипотезы о новых путях или их отсутствии, о переходах, а равно и препятствиях.

С рациональной точки зрения обязательство выглядит как пребывающий в движении каскад ветвящихся путей. Его фронтиры расширяются, он развивается в развертывающийся ландшафт, его фиксированные перспективы приходят в движение, вырывается укорененность любой формы, связанная с закрепленным обязательством или неизменными ответственностями, связи и отсылки между старыми и новыми обязательствами подвергаются пересмотру, и, наконец, стирается всякий образ себя как «того, чем оно должно было быть».

Поместить значение человека в рациональную систему обязательств - значит подчинить предполагаемую стабильность этого значения тревожащей и преобразующей силе ландшафта, претерпевающего обширные изменения под ревизионным напором его разветвляющихся маршрутов. Размещая себя внутри рациональной системы обязательств, гуманизм утверждает себя как исходное условие того, что уже задним числом едва ли похоже на то, что изначально привело его в движение. Мы покажем, что достаточно разработанный гуманизм является сходным условием ингуманизма как силы, которая движется назад из будущего, чтобы изменить, если не полностью подорвать, власть своего истока; другими словами, это будущее, пишущее свое собственное прошлое.

\section{5. Образ человека, начертанный на песке}

Практическая разработка взятия обязательства в отношении человечества и есть ингуманизм. Если взять обязательство - значит полностью разработать содержание такого обязательства (последовательное вопрошание «что еще?» в отношении того, что значит быть человеком) и если быть человеком - значит быть способным вступить в пространство разума, то в обязательстве в отношении человечества необходимо полностью раскрыть, как способности разума функционально преобразуют чувственность в разумность.

Но так как разум обладает функциональной автономией - и она позволяет ему не допускать схлопывания разумности обратно в чувственность, - полная разработка способностей разума влечет за собой распаковку следствий автономии разума для челове- 
ка. Гуманизм по определению является проектом расширения пространства разума путем разработки того, что следует из автономии разума, и тех требований, которые она на нас накладывает. Но автономия разума подразумевает, что он самостоятельно оценивает и конструирует себя и, соответственно, самостоятельно пересматривает и конструирует то, отличительной чертой чего является вхождение в пространство резонов. Иначе говоря, для человечества последствия материализации самокультивации разума - самой сути функциональной автономии разума - потрясающи. Что разум делает с собой, неизбежно проявляется в том, что он делает с человеком.

Поскольку функциональная автономия разума предполагает его самоопределение в том, что касается собственного поведения, - ведь разум не может оцениваться или пересматриваться ничем, кроме себя самого (во избежание искажений и предрассудков), - обязательство в отношении такой автономии размыкает то, что значит быть человеком, для решительной ревизии со стороны разума. В известном смысле автономия разума - это автономия его власти подвергать пересмотру; обязательство в отношении автономии разума (через проект гуманизма) - это обязательство в отношении автономии его ревизионной программы, которую человек не контролирует.

Ингуманизм и является активацией ревизионной программы разума, направленной против автопортрета человечества. Как только структура и функция обязательства будут по-настоящему поняты, мы увидим, что оно прокладывает себе путь назад из будущего, из обязательств, сопутствующих текущему обязательству, подобно разъедающей кислоте пересмотра, устремляющейся назад во времени. Разрушая скрепляющую связь между нынешними обязательствами и их прошлым, рассматривая нынешние обязательства с точки зрения их последствий, пересмотр вызывает каскадное обновление этих обязательств, которое глобально распространяется по всей системе. Рациональная структура обязательства - в данном случае это «обязательство в отношении человечества» - конструирует возможности настоящего, культивируя позитивные тенденции прошлого посредством пересматривающих сил будущего. Взяв обязательство в отношении человека, вы фактически начинаете уничтожать его канонический портрет исходя из будущего. Как выразился Фуко, можно поручиться, что автопортрет человека исчезнет, как лицо, начертанное на прибрежном песке ${ }^{12}$. Каждый на-

12. См.: Фуко М. Слова и вещи. Археология гуманитарных наук. СПб.: А-cad, 1994. C. 404. 
рисованный портрет смывается ревизионной властью разума, уступая место более утонченным портретам, в которых так мало канонических черт, что вполне можно спросить, стоит ли, полезно ли вообще называть то, что осталось, «человеком».

Ингуманизм - это работа рациональной агентности над человеком. Нужно только учесть: рациональная агентность не является ни личной, ни индивидуальной, ни даже обязательно биологической. Ядро ингуманизма - обязательство в отношении человечества, которое реализуется одновременно через конструирование и пересмотр человека, направляемые и регулируемые автономией разума, то есть его самоопределением и ответственностью за собственные потребности. В пространстве разума конструирование ведет к пересмотру, а пересмотр требует конструирования. Пересмотр предполагаемого портрета человека подразумевает, что конструирование человека вне зависимости от контекста возможно без обращения к конститутивному основанию, фундаментальной идентичности, непорочной природе, данному смыслу или априорному состоянию. Словом, пересмотр - это разрешение на дальнейшее конструирование.

\section{6. Когда мы потеряли связь с «тем, что из нас получается»}

Если, как отмечает Майкл Феррер, антигуманизм занят невыполнимой задачей по устранению смешения человеческой значимости с преклонением перед ним, то ингуманизм - это проект, который начинается с отделения значимости человека от его славы ${ }^{13}$. Рассеивая содержание смешения и очищая значимость от остатков преклонения, ингуманизм затем доводит гуманизм до его предельных заключений: конструирует доступный для пересмотра образ нас самих, который освобождается в функциональном плане от наших ожиданий и исторических предрассудков о том, каким этот образ должен быть, как должен выглядеть или что значить. Поэтому ингуманизм, как будет показано ниже, инициирует новую фазу систематического проекта эмансипации - не в качестве преемника других форм эмансипации, но как критически настоятельная и необходимая добавка к растущей цепи обязательств.

Более того, ингуманизм отбрасывает ожидание будущего, которое основано на описаниях и предписаниях, вытекающих из консервативного гуманизма. Консервативный гуманизм подчиняет

13. См.: Ferrer M. Human Emancipation and "Future Philosophy". Falmouth: Urbanomic, 2015. 
консеквенциальность человеческого сверхдетерминированному смыслу или сверхконкретизированным описаниям, которые неизменны и во что бы то ни стало должны сохраняться в любом предписании, разработанном человеком и для человека. Ингуманизм, наоборот, привязывает консеквенциальность обязательства по отношению к человечеству к его практической разработке и навигации по его ветвящимся следствиям. Ибо настоящая консеквенциальность обязательства заключается в его способности генерировать дальнейшие обязательства, обновлять себя в соответствии со своими разветвлениями, открывать пространства возможностей и работать с ревизионными и конструктивными смыслами, которые такие возможности могут нести в себе.

Соответственно, консеквенциальность обязательства по отношению к человечеству не заключается в том, как изначально описываются или устанавливаются его параметры. Она связана с тем, как переплетаются прагматическое значение этого обязательства (значение как употребление) и функционалистский смысл его описаний (что мы должны делать, чтобы считаться людьми?), чтобы реализовывать самые разные следствия, несовместимые с тем, что было в начале. Консеквенциальность в этом смысле приходит на смену консеквенциальности в старом смысле и путем тщательного пересмотра сполна доказывает ее дескриптивную бедность и непоследовательность ее предписаний.

Поскольку, как замечает Роберт Брэндом, «каждое следствие - это изменение в нормативном статусе», которое может привести к несовместимостям между обязательствами ${ }^{14}$, мы должны предпринять особые действия для разрешения этих несовместимостей, дабы удержать обязательство. С точки зрения ингуманизма чем сильнее разрывы между следствиями из связывания себя обязательством в отношении человечества, тем сильнее требования сделать что-то (что-то этическое, юридическое, экономическое, политическое, технологическое и т. д.) для исправления наших предприятий. Ингуманизм подчеркивает, что необходимо действовать в соответствии с вмешательством пересмотра, которое все больше проявляет себя как дискретность, как растущий разлом без всякой возможности его залатать.

Любое социально-политическое устремление или последовательная программа перемен должны в первую очередь обратиться к этому разлому или эффекту дискретности и затем уже продумать в соответствии с ним необходимый план действий. Одна-

14. Brandom R. Between Saying and Doing. P. 191. 
ко сделать что-то по поводу эффекта дискретности - вызванного непредвиденными последствиями и вытекающими из них экспоненциально растущими переменами в нормативном статусе (требований того, что должно быть выполнено) - не равносильно акту восстановления. Напротив, задача состоит в том, чтобы построить точки связывания - когнитивные и практические каналы, - чтобы сделать возможной коммуникацию между тем того, что мы думаем о себе, и тем, что из нас получается.

Умение распознать это последнее - не дарованное право и не неотъемлемая естественная способность, здесь все дело в работе, программе, причем такой, которая в принципе отсутствует в сегодняшних политических проектах. Быть человеком ни в коей мере не означает умения подключаться к следствиям того, что значит быть человеком. И точно так же тот факт, что мы идентифицируем себя как людей, не является достаточным условием ни понимания того, что из нас получается, ни осознания того, чем мы становимся, или, точнее, что из нас рождается.

Политическое устремление, соотносящее себя с антигуманизмом, не может предотвратить его скатывание к гротескной форме активизма. Но любая социально-политическая программа, присягающая на верность консервативному гуманизму - либо через квазиинструменталистский или охранительный подход к разуму (вроде хабермасовской рациональности), либо через теологически нагруженное значение человека, - тем самым упрочивает тиранию текущего момента под эгидой служащего основанием прошлого или истока.

Антигуманизм и консервативный гуманизм представляют собой две патологии истории, которые часто появляются под рубриками сохранения и прогресса: один требует от настоящего сохранять черты прошлого, другой требует от него стремиться в будущее, оставаясь укорененным в прошлом. Но катастрофа пересмотра отключает их от будущего, изменяя связь между прошлым и настоящим, транслируя катастрофическую концепцию времени, в которой ветвящиеся следствия избыточны по отношению к их истоку.

\section{7. Катастрофа пересмотра}

Определение человечества согласно разуму - минималистское определение, следствия которого не даны непосредственно, но ветвления которого потрясают. Если бы когда-нибудь и приключился истинный кризис, то он заключался бы в нашей неспо- 
собности справиться со следствиями придерживания обязательства в отношении подлинного содержания человечества. Траектория разума - это траектория всеобщей катастрофы, у точечных событий и пошаговых течений которой нет наблюдаемого эффекта или всеобъемлющей дискретности. Таким образом, разум - это одновременно и медиум стабильности, упрочивающий процедурность, и всеобщая катастрофа, медиум радикального изменения, обеспечивающий прерывистую тождественность разума предвосхищаемому образу человека.

В ходе разработки человечества в дискурсивном пространстве разума устанавливается разрыв между предвосхищением человеком самого себя (того, чем он ожидает стать) и образом человека, модифицированным в соответствии с его активным содержанием или значением. Именно эта прерывистость характеризует ингуманизм как всеобщую катастрофу, приуготовляемую активацией содержания человечества, чье функциональное ядро не просто автономно, но также принуждает и преобразует.

Для распознания человечества требуется активация автономного пространства разума. Но поскольку это пространство - будучи содержанием человечества - функционально автономно даже несмотря на то, что его происхождение исторично, его активация подразумевает деактивацию исторических ожиданий относительно того, чем человечество может быть или стать, на дескриптивном уровне. Поскольку антигуманизм черпает свою критическую силу в основном на этом дескриптивном уровне - размещается ли он в природе (предположительно неуязвимой для пересмотра) или в узком историческом поле (основываясь на конкретном ожидании), - реализация автономии разума восстановила бы нетеологическое значение человека как начальное необходимое условие, тем самым аннулировав антигуманистическую критику. Здесь важно понять, что нельзя отстаивать ингуманизм или даже говорить о нем, не связав себя сперва обязательством с гуманистическим проектом напрямую через Просвещение.

Рационализм - это принудительная навигация по пространству разума. Он превращает обязательство в отношении человечества в ревизионную катастрофу, преобразовывая его исходное обязательство в ветвящийся каскад сопутствующих обязательств, которые требуют навигации, чтобы первое обязательство могло считаться обязательством. Но именно это преобразование, спровоцированное и направляемое разумом, трансформирует обязательство в ревизионную катастрофу, которая движется обратно во времени из будущего, из его ревизионных ответвлений, чтобы вмешаться 
в прошлое и переписать настоящее. В этом смысле разум учреждает в истории связь, до сих пор непредставимую с точки зрения настоящего, которое сохраняет исток или укоренено в прошлом.

Действовать в тандеме с ревизионным вектором будущего значит вовсе не спасать, а обновлять и перерабатывать, восстанавливать и модифицировать. С точки зрения когнитивной и практической адаптации к реальности времени как предварительному условию воздействия на историю спасение представляется не более чем теологической странностью. Оно проистекает из неправильного понимания времени, из смешения или тривиализации связей между прошлым, настоящим и будущим и, наконец, из предвзятого предпочтения истока назначению. Но реальность времени не исчерпывается истоком или тем, что уже случилось; напротив, именно судьба, разворачиваясь, заставляет нас пересматривать свои позиции и ориентации.

Судьба выражает реальность времени как избыточную и асимметричную по отношению к началу; по сути, как катастрофичную по отношению к нему. Но назначение - вовсе не одна-единственная точка или конечная цель, оно принимает вид траекторий: как только определенная цель достигнута или выполняется, она перестает управлять ведущей к ней исторической траекторией и заменяется рядом более новых назначений, которые начинают управлять разными частями траектории, приводя ее к разветвлению на много траекторий. Именно так фактически и устраняются все рудименты конечной цели в истории. Дело в том, что исток вымывается концепцией времени, появляющегося под видом судьбы, которая достигается поступательно, хотя на самом деле судьба возвратно пишет себя из множества назначений в будущем.

Конструктивно-ревизионная петля ингуманизма показывает, что нет никакой несовместимости между судьбическим проектом и отсутствием конечной цели, между исторической самореализацией и пустотой времени. Спасение, будучи активистским импульсом, оперирует как волюнтаристический модус действия, ведомый охранительным или консервативным подходом к настоящему. Пересмотр, напротив, есть требование, рационально принуждающее отдаться ревизионным волнам будущего, которые запускает функциональная автономия разума.

\section{8. Автономия разума}

В чем же состоит функциональная автономия разума? Это выражение расположенности разума к самоактуализации - сцена- 
рий, в котором разум освобождает собственные пространства вопреки тому, что естественно кажется необходимым, или тому, что произошло. Здесь «необходимое» указывает на предполагаемую природную необходимость, которую следует отличать от нормативной необходимости. Если данность природных причин определяется посредством «есть» (что-то предположительно имеет место, так как контингентно установилось, например атмосферные условия планеты), то нормативность рационального определяется через «должно быть». Первое выражает предположительно необходимый стимул или импульс, тогда как последнее не дано, а порождается открытым признанием закона или нормы, неявно задаваемой коллективной практикой, благодаря которому закон или норма и переводится в обязывающий статус, в понятийную компульсию, в долженствование.

Именно это измерение должного, связанное с признанием, устойчивое к ошибкам и ревизионное - в отличие от импульсивного диктата закона природы, - предъявляет долг как вектор конструирования, который превращает контингентно полагаемые природные необходимости в управляемые переменные, нужные для построений. Кроме того, порядок должного допускает составление функциональной организации, цепочки или династии долгов, которая процедурно реализует совокупный побег от якобы необходимого «есть», кристаллизованного в порядке здесь-и-сейчас.

Функциональная автономия разума состоит в подключении простых долгов к сложным долгам, нормативным необходимостям или способностям через инференциальные связи или процессы. Обязательство в отношении человечества и, следовательно, автономия разума требуют не только уточнения, на какие долженствования или способности взять обязательство мы правомочны, но и развития новых функциональных связей и путей выводов, которые соединят существующие долги с новыми долженствованиями или обязанностями.

Будь то марксистская повестка, кредо гуманизма или направленный в будущее взгляд, любая политическая философия, которая хвалится своими обязательствами, не решая при этом выводные проблемы и не строя инференциальные и функциональные связи, страдает от внутренней противоречивости и отсутствия взаимной подключенности обязательств. Без инференциальных связей не может быть никакого реального обновления обязательств. Без глобальной программы обновления становится все труднее, если не невозможно, предотвращать застаивание гуманизма, превра- 
щающее его в инструмент консерватизма, и скатывание марксизма в карикатуру на критику, мешанину увещеваний и революционной бравады. Неважно, насколько социально-политически искусным или решительным кажется политический проект - без глобальной системы обновления внутренние противоречия такого предприятия не дадут ему предписать никакую обязанность или долг.

Так, «Манифест акселерационистской политики» Срничека и Уильямса (достойная попытка очертить то, «что должно быть сделано» в плане функциональных организаций, сложных иерархий и обратных положительных связей автономии) - это марксистский проект, находящийся в процессе обновления своих обязательств. Неудивительно, что сильнее всего он осмеивается и презирается теми течениями марксизма, которые уже давно отказались от обновления своих когнитивных и практических обязательств.

\section{9. Функциональная автономия}

Говоря о функциональной автономии разума, мы не имеем в виду его генетическую спонтанность, поскольку разум историчен и открыт для пересмотра, социален и укоренен в практике. На самом деле здесь заявляется об автономии дискурсивных практик и автономии инференциальных связей между долженствованиями, то есть связей между способностями к построению и обязанностями по ревизии. Разум коренится в социальном конструировании, в коллективной оценке и в управляемости импликаций, вложенных в способы вывода. Отчасти он социален потому, что тесно связан с происхождением и функцией языка как де-приватизирующего, коллективного и стабилизирующего пространства организации. Однако следует быть осторожными при выведении «здравой» концепции социального, так как стандартная отсылка к социальной конструкции рискует не только привести к релятивизму и двусмысленности, но и, как показывает Пол Богоссян, к страху перед (по)знанием ${ }^{15}$. Первый шаг в направлении выведения такой здравой концепции социального - провести необходимое различие между «неявно» нормативным аспектом социального (сфера потребления и производства норм через практики) и измерением социального, наполненным конвенциями, между нормами как установками вмешательства и нормализующими нормами как конформистскими диспозициями.

15. См.: Boghossian P. A. Fear of Knowledge: Against Relativism and Constructivism. Oxford: Oxford University Press, 2006. 
Разум начинается с установки вмешательства по отношению к неявным нормам, задаваемым социальными практиками. Он не отделен ни от природы, ни от социальной конструкции. Однако у него есть только ему присущие нередуцируемые потребности (Кант) и конститутивная самодетерминация (Гегель), он может быть оценен только самим собой (Селларс). По сути, первая задача или вопрос рационализма - представить такую концепцию природы и социального, в которой будет предусмотрена автономия разума. Этот вопрос касается каузального режима природы, который оставляет возможность для автономной деятельности разума по «признанию» законов, будь то естественных или социальных. Поэтому важно отметить, что рациональность - это не поведение в соответствии с законом, а признание закона. Рациональность - это «концепция закона» как портала в область правил, доступных для пересмотра и навигации. Мы становимся рациональными агентами только тогда, когда признаем или развиваем ту или иную установку вмешательства в отношении норм, которая придает им обязательность. Мы не принимаем нормативный статус вещей напрямую. У нас нет доступа к эксплицитному, то есть логически кодифицированному, статусу норм. Но мы проясняем статус норм именно с помощью таких установок вмешательства в отношении пересмотра и конструирования норм посредством социальных практик ${ }^{16}$. Вопреки Гегелю, рациональность не кодифицируется явными нормами от и до. Путать неявные нормы, доступные через практики вмешательства, с явными нормами - обычное дело, и оно сопряжено с риском впадения в логицизм или интеллектуализм, то есть такое понимание нормативности, при котором эксплицитные нормы конституируют исходное состояние, а правила стоят на правилах, те на правилах и так без конца, - идея, уже опровергнутая витгенштейновским аргументом против регресса ${ }^{17}$.

\section{0. Функциональный бутстрепинг и практическая разложимость}

Автономия разума - это утверждение об автономии его нормативной, инференциальной и пересматривающей функций по отношению к обусловливающей его причинной цепи. В конечном

16. См.: Brandom R. Making It Explicit: Reasoning, Representing, and Discursive Commitment. Cambridge, MA: Harvard University Press, 2001.

17. См.: Витгенштейн Л. Философские исследования // Филос. раб. Ч. 1. М.: Гнозис, 1994. \$110. 
счете это (нео)функционалистский тезис в смысле прагматического или рационалистического функционализма. Следует отличать прагматический функционализм как от традиционного ИИ-функционализма, завязанного на символической природе мысли, так и от бихевиоральных вариантов функционализма, которые полагаются на поведение как набор регулярностей. Хотя последние две разновидности функционализма чреваты разнообразными мифами панкомпьютационализма (безусловная вездесущность вычисления, представление, что любая физическая система может реализовать любое вычисление) или бихевиоризма, важно отметить, что полный отказ от функционализма в его прагматическом или кантианском рационалистическом смысле непременно приведет к витализму и танцам вокруг невыразимости, то есть мистической догме, согласно которой в мысли есть что-то сущностно особое и недоступное для артикулирующего построения.

Прагматический функционализм тематизирует прагматический характер человеческих дискурсивных практик, то есть способность рассуждать, пошагово двигаться от слов к действиям и обратно. «Пошаговость» здесь определяет устройство слов и действий, утверждений и исполнений как условие почти полной разложимости. Таким образом, прагматический функционализм сосредоточивается на разложимости дискурсивных практик на недискурсивные, он отвечает на вопрос: «Что ты должен делать, чтобы считаться рассуждающим или даже мыслящим?» В отличие от символического или классического ИИ, прагматический функционализм не раскладывает имплицитные практики на эксплицитные, то есть логически кодифицируемые, нормы. Он занят практической разложимостью, а не алгоритмической, немонотонными процедурами, а не монотонными операциями. Вместо этого он раскладывает эксплицитные нормы на имплицитные практики, знание-что на знание-как (сфера способностей, обладающих потенциалом бутстрепинга: что следует сделать, чтобы считаться исполняющим что-то конкретное?).

Согласно прагматическому или рационалистическому функционализму, автономия разума влечет его автоматизацию, поскольку автономия практик, будучи отличительной чертой разумности, предполагает автоматизацию дискурсивных практик посредством их практической разложимости на недискурсивные практики. Автоматизация дискурсивных практик, или петля обратной связи между словами и делами, - это подлинное выражение функциональной автономии разума и цель программы по расколдовыванию мира. Если мысль способна расколдовать природу, 
то только автоматизация дискурсивных практик способна расколдовать саму мысль.

Здесь под автоматизацией не имеется в виду однообразное повторение процессов, нацеленное на эффективную оптимизацию или строгие формы логического следования (монотонность). Это регистр функционального анализа или практической разложимости ряда специальных действий, обеспечивающий независимость получения одного набора способностей от другого. Соответственно, автоматизация здесь сводится к практическому расширению возможностей (enablement), или способности поддерживать и усиливать функциональную автономию или свободу. Прагматические процедуры, задействованные в этом модусе автоматизации, постоянно диверсифицируют область действий и познания постольку, поскольку немонотонность практик раскрывает новые траектории практической организации и, соответственно, расширяет область практической свободы.

Как только игра разума как сфера правилосообразных практик запущена, разум способен самостоятельно получать сложные способности из примитивных. Это не что иное, как самоактуализация разума. Он высвобождает собственные пространства и требования, в процессе основательно пересматривая не только то, что мы понимаем под мышлением, но и то, что мы называем «мы». Где есть функциональная автономия, там есть и возможность самоактуализации или самореализации как эпохальное достижение истории. Везде, где разворачивается самореализация, там устанавливается замкнутый контур обратной положительной связи между свободой и интеллектом, трансформацией себя и пониманием себя. В таком случае функциональная автономия разума является предтечей самореализации интеллекта, который собирает себя по частям из констелляции «мы», служащего для дискурсивной разработки в качестве самости с открытым исходным кодом (open source self).

Следовательно, рационалистический функционализм намечает несимволический, то есть философский, проект общего интеллекта (general intelligence), в котором интеллект исчерпывающе схвачен как вектор самореализации путем поддержания и усиления функциональной автономии. Автоматизация дискурсивных практик - прагматическое высвобождение искусственного общего интеллекта и запуск новых форм коллективизирующих практик через подсоединение к автономным дискурсивным практикам - воплощает собой ревизионное и конструктивное острие разума, наточенное против канонического автопортрета человека. 
Чтобы быть свободным, надо быть рабом разума. Но становящийся рабом разума (само условие свободы) открывается для властного пересмотра и принуждения к конструированию со стороны разума. Эта восприимчивость предельно усиливается, когда обязательство по отношению к автономии разума и автономное занятие дискурсивными практиками разработаны в достаточной мере. Другими словами, когда автономия разума понята как автоматизация разума и дискурсивных практик - это философский, а не классический символический тезис об искусственном общем интеллекте ${ }^{18}$.

\section{1. Дополненная рациональность (augmented rationality)}

Автоматизация разума знаменует собой новую фазу расширения возможностей лезвия пересмотра и вектора конструирования разума. Эта новая фаза расширения возможностей разума сигнализирует об усилении различия между рациональной компульсией и природным импульсом, между «должно» как обязательством вмешательства и «есть» как подчинением предположительному или естественному порядку вещей (контингентность природы, необходимость основания, диспозиции, конвенции и якобы необходимые ограничения).

Динамическое заострение различия между «есть» и «должно» возвещает о появлении того, что следует назвать дополненной рациональностью. Она дополнена не в том смысле, что более рациональна (как и дополненная реальность не более реальна, чем реальность), а в смысле дальнейшей радикализации различия между тем, что было сделано или случилось (или предположительно имеет место), и тем, что должно быть сделано. Только заострение этого различения способно дополнить требования разума и, соответственно, подтолкнуть рациональную агентность к новым фронтирам деятельности и познания.

Дополненная рациональность - это радикальное усиление различия между «должно» и «есть». Тем самым, с определенной точки зрения, она отменяет миф о восстановлении и стирает любую надежду на примирение между бытием и мышлением. Дополненная рациональность, по словам Говарда Баркера, действует в «зоне

18. О связи философии и искусственного интеллекта см.: Deutsch D. Philosophy Will Be the Key That Unlocks Artificial Intelligence//The Guardian. 03.10.2012. URL: http://theguardian.com/science/2012/oct/o3/ philosophy-artificial-intelligence. 
максимального риска» - риска не для человечества как такового, а для обязательств, не успевших обновиться из-за того, что они соответствуют тому портрету человека, который был пересмотрен $^{19}$. Понятая как труд нечеловеческого, дополненная рациональность приводит к обобщенной катастрофе для необновленных обязательств в отношении человека - приводит посредством усиления пересмотра и конструирования как измерений «должно». Если у разума есть собственная функциональная эволюция, то когнитивное неподчинение адаптации к пространству разума (эволюции долженствования, а не природной эволюции «есть») заканчивается катастрофой.

В адаптации к эволюции разума, то есть в актуализации разума согласно его собственным функциональным требованиям, все дело в обновлении обязательств в отношении автономии разума путем обновления обязательств в отношении человека. Обновление обязательств невозможно без перевода пересмотра и конструирования как измерений разума в систематические проекты пересмотра и конструирования человека посредством коллективного оценивания и методологического коллективизма. Хотя рационализм представляет систематичность пересмотра и конструирования, он не может сам учредить эту систематичность. Иными словами, рационализм не заменяет политический проект, хотя и остается необходимой платформой, которая одновременно наполняет и ориентирует любой последовательный политический проект.

\section{2. Культивирующий проект конструирования и пересмотра}

Автоматизация разума и дискурсивных практик размыкает новые перспективы применения пересмотра и конструирования, то есть участия в систематическом проекте практической свободы. Это свобода, понятая и как систематичность знания, и как (по)знание системы, являющееся условием воздействия на нее. Чтобы воздействовать на систему, необходимо ее знать. Но коль скоро система есть не что иное, как глобальное слияние тенденций и функций, и коль скоро у нее нет ни внутренней архитектуры, ни окончательного основания, ни внешнего предела, дабы познавать ее, к ней необходимо относиться как к конструируемой гипотезе. Другими словами, система должна быть понята через

19. Barker H. Arguments for a Theater. Manchester: Manchester University Press, 1997. P. 52. 
абдуктивный синтез и дедуктивный анализ, методическое конструирование и инференциальное управление ее разноуровневыми переменными.

Знание системы - это не общая эпистемология, а «инженерная эпистемология» (engineering epistemology), как подчеркивает Уильям Уимсатт ${ }^{20}$. Инженерная эпистемология - форма познания, которая включает в себя нацеленное управление причинно-следственной тканью и организацию функциональных иерархий, - является обновляемым арсеналом эвристик, которые особенно внимательны к различающимся ролям и требованиям разных уровней и иерархий. Она использует сущности и механизмы более низких уровней, чтобы направлять и усиливать конструирование на более высоких уровнях. Кроме того, инженерная эпистемология использует переменные более высоких уровней и устойчивые процессы, чтобы корректировать структурные и функциональные иерархии уровней ниже ${ }^{21}$, а также заново нормализировать их пространство возможностей ради актуализации их конструктивных потенциалов, тем самым делая наблюдаемые характеристики и условные конструкции управления необходимыми для дальнейшего конструирования ${ }^{22}$.

Любой политический проект, нацеленный на настоящее изменение, должен понимать логику вложенных иерархий, являющуюся характерной чертой сложных систем ${ }^{23}$, и адаптироваться к ней. Дело в том, что изменение может осуществиться только в результате

20. Wimsatt W. C. Re-Engineering Philosophy for Limited Beings: Piecewise Approximations to Reality. Cambridge, MA: Harvard University Press, 2007.

21. Подробные и технические определения процессов и механизмов см.: Seibt J. Forms of Emergent Interaction in General Process Theory//Synthese. 2009. Vol. 166. № 3. P. 479-512; Craver C. F. Role Functions, Mechanisms and Hierarchy // Philosophy of Science. 2001. Vol. 68. № 1. P. 53-74.

22. Условные конструкции управления (manipulation conditionals) - специфические формы общих условных конструкций, которые выражают разные каузальные и объяснительные сочетания антецедентов и консеквентов (если... то...) применительно к вмешательствам или управляемым гипотезам. Например, простым кондиционалом управления является: если бы $x$ было управляемо при наборе параметров $W$, то оно бы себя вело как $y$. О теории каузальных и объяснительных вмешательств см.: Woodward J. Making Things Happen: A Theory of Causal Explanation. Oxford: Oxford University Press, 2003.

23. Реалистская трактовка сложности изложена в: Ladyman J. et al. What is a Complex System? // European Journal for Philosophy of Science. 2013. Vol. 3. № 1. P. 33-67. А более детальное изложение см. в: Badii R., Politi A. Complexity: Hierarchical Structures and Scaling in Physics. Cambridge: Cambridge University Press, 1999. 
и структурных модификаций, и функциональных преобразований в разных структурных слоях и на разных функциональных уровнях. Распределение вложенных структурных и функциональных иерархий порождает многочисленные сложности. Иногда, чтобы произвести изменение на одном уровне, нужно сделать структурное или функциональное изменение на другом, вроде бы не связанном с ним уровне. Более того, важно изменять функции (на экономическом, социальном или политическом уровне). Однако не всякое структурное изменение с необходимостью ведет к функциональному изменению. В то же время всякое функциональное изменение - в силу того, что для системы функции играют роль целедостижения и динамической стабилизации, - приводит к структурному изменению (хотя такое структурное изменение может не произойти в конкретной структуре, функция которой только что изменилась).

Важность вложенных иерархий для осуществления изменения любой формы в любом пласте нашей жизни делает крайне необходимым знание разных объяснительных уровней и межуровневое управление. Такое знание еще предстоит полностью встроить в политические проекты. Без знания структурных и функциональных иерархий любая претензия на изменение - посредством модификации, реорганизации или локального подрыва - дезориентируется из-за смешения структурных и функциональных слоев на экономическом, социальном и политическом уровнях. Изменение, которое не решает проблему объяснительного и описательного, структурного и функционального смешения, в конечном счете заново вписывает смешение под видом решения, что является просто еще одним усложнением в другом слое или в другом регионе. Поэтому только объяснительная дифференциация уровней и межуровневое управление (комплексные эвристики) могут превратить мечты о переменах в реальность.

В иерархическом сценарии параметры более низкого уровня раскрывают уровни выше пространствам возможностей, что одновременно расширяет возможность конструирования и порождает возможность пересмотра. В то же время дескриптивная пластичность и стабилизированные механизмы более высоких уровней регулируют и мобилизуют конструирование и управление на более низких уровнях. Способности нижних и верхних уровней в сочетании друг с другом образуют инженерную петлю пересмотраконструирования. Инженерная петля обходит неадекватности и эмерджентизма, и элиминативного редукционизма и является схемой перспективы и картой синтеза. В качестве карты (математического отображения) она распространяется по разным уров- 
ням, а как множество покрывающих карт с разными дескриптивно-прескриптивными валентностями - по индивидуальным слоям. Лоскутная структура обеспечивает пластичность описаний и гибкость предписаний, она редуцирует непоследовательности и объяснительные смешения и делает эффективным поиск проблем и возможностей конструирования, адаптируя дескриптивные и прескриптивные покрывающие карты к конкретным параметрам и регионам. Как компас перспектив, инженерная петля проходит через наличный и научный образы (стереоскопическая связность), допускает вид сверху и вид снизу (телескопическое углубление) и интегрирует различные мезомасштабы, у которых есть собственные и нетиражируемые объяснительные, описательные, структурные и функциональные порядки (нетривиальный синтез). Петля пересмотра-конструирования всегда учреждает инжиниринг как реинжиниринг, процесс повторной модификации, повторной оценки, переориентации и переустройства. Именно совокупный эффект инжиниринга (Уимсатт) соответствует функциональному и структурному накоплению сложных систем ${ }^{24}$, как та разъедающая субстанция, которая постепенно разрушает мифы основания и ускоряет совокупный побег от контингентных параметров.

Устойчивые к ошибкам и управляемые аспекты, возникающие при отношении к системе как гипотезе, и инженерная эпистемология как раз и выражают пересмотр и конструирование как две центральные функции свободы. Всякое обязательство, которое препятствует пересмотру и не поддерживает - или, что важнее, не расширяет - область конструирования, должно быть обновлено. Если же его нельзя обновить, от него следует отказаться. Свобода порождается только функциональным накоплением и совершенствованием, которые являются характеристиками иерархических, вложенных, а потому децентрализованных и сложных систем. Функциональная организация состоит из функциональных иерархий и правильных инференциальных связей между ними, которые делают возможными нетривиальную ориентацию, поддержание, калибровку и усиление. Таким образом они создают условия для процедурного преобразования предположительных необходимостей и связанных с природными причинами оснований в управляемые переменные конструирования.

В некотором смысле функциональную организацию можно интерпретировать как сложную иерархическую систему функциональных связей и функциональных свойств, относящихся как к норма-

24. Cм.: Wimsatt W. C. Re-Engineering Philosophy for Limited Beings. 
тивному, так и к причинному функционированию. Она способна превращать порядок данный в порядок вмешательства и уполномочивания - «есть» в «должно», - при этом контингентно сложившиеся природные пределы заменяются необходимыми, но пересматриваемыми нормативными ограничениями. Важно отметить, что конструирование ведется в условиях нормативных, а не природных ограничений и природных детерминаций (отсюда реализм), которые не могут считаться фундирующими пределами. Функциональные иерархии играют роль лестниц или самонастроек, посредством которых одна причинно-следственная ткань присваивается другой, нормативный статус одного уровня продвигается на другой уровень.

Вот почему фигура инженера как агента пересмотра и конструирования является главным общественным врагом основания как того, что ограничивает область изменения и блокирует возможности кумулятивного побега. Он - не защитник трансгрессии и не воинствующий коммунитарист, решительно настроенный изъять себя из системы или сплющить систему до состояния горизонтальности. Что важнее, именно поэтому свобода не является предметом экспресс-доставки, будь то во имя спонтанности либо воли народа или же во имя экспорта демократии. Освобождение - это проект, а не идея или товар. Его следствие - не прерывающее вторжение новшества, а непрерывность учрежденной формы труда.

Условие свободы не освобождение, а постепенное структурное и функциональное накопление и совершенствование, которые принимают форму проекта самокультивации. Они создают подходящую среду для обновления обязательств как через корректировку влияний уровней друг на друга, так и через конструктивную предрасположенность, которая встроена в функциональные иерархии как моторы уполномочивания.

Освобождение не является ни первичной искрой свободы, ни достаточным ее содержанием. Считать освобождение источником свободы - значит проявлять излишнюю доверчивость к событийности; установка, которая не раз доказывала свою несостоятельность, поскольку не гарантирует поддержание и усиление свободы. Но если считать освобождение достаточным содержанием свободы, это приводит к еще худшему результату: таковы иррационализм и, как следствие, возникновение разных форм тирании и фашизма.

Достаточное содержание свободы можно найти только в разуме. Нужно признать разницу между рациональной нормой и законом природы, между эмансипацией, свойственной последовательному признанию обязательности подчинения разуму, и рабством, связанным с утратой такой способности признать - утратой, ко- 
торая является условием подчиненности действий природным импульсам. Строго говоря, свобода - это не освобождение от рабства. Это непрерывное отучение от рабства.

Двумя необходимыми аспектами этой процедуры отучения являются принуждение обновлять обязательства и принуждение (compulsion) конструировать когнитивные и практические технологии для реализации таких обновлений. С точки зрения конструирования и пересмотра свобода - это интеллект. Обязательство по отношению к человечеству или свободе, которое в практике не разрабатывает значение этого тезиса, тем самым уже забыло свой долг и взяло человечество в заложники лишь для того, чтобы промучиться в истории пару-тройку дней.

Либеральная свобода, будь она социальным предприятием или интуитивной идеей свободы от нормативных ограничений (то есть свободы без цели или направленной деятельности), 一это свобода, непереводимая в интеллект и поэтому задним числом устаревшая. Переустроить предполагаемое устройство, провести функциональную связь между определением нормативно благого и его воплощением в жизнь, поддержать и усилить благо и наделить стремление к лучшему собственной автономией - таков ход свободы. Это и определение интеллекта как самореализации практической свободы и функциональной автономии, которая освобождает себя вопреки своему устройству.

Приспособление к автономной концепции разума, то есть обновлению обязательств в соответствии с прогрессивной самоактуализацией разума, - это борьба, совпадающая с проектом свободы как пересмотра и конструирования. Первейшим выражением такой свободы является установление ориентации - руководящего указателя, высвечивающего синтетический и конструктивный путь, по которому должен следовать человек. Но чтобы идти по этому пути, мы должны перейти когнитивный Рубикон.

Более того, установка вмешательства, требуемая адаптацией к функционально автономному разуму, предполагает, что Рубикон уже перейден. Чтобы двигаться по этому пути синтеза, нет смысла оглядываться назад на то, что однажды было, но истаяло как мираж под напором ревизионных ветров разума ${ }^{25}$.

25. Я выражаю признательность Майклу Ферреру, Брайану Вуду, Робину Маккею, Бенедикту Синглтону, Питеру Вулфендейлу и многим другим, кто внес вклад в этот текст своими предложениями или участием в обсуждении. Всеми своими достоинствами это эссе обязано им, недостатки же его-на моей совести. 


\section{Библиография}

Витгенштейн Л. Философские исследования // Филос. раб. Ч. 1. М.: Гнозис, 1994. Фуко М. Слова и вещи. Археология гуманитарных наук. СПб.: А-cad, 1994.

Badii R., Politi A. Complexity: Hierarchical Structures and Scaling in Physics. Cambridge: Cambridge University Press, 1999.

Barker H. Arguments for a Theater. Manchester: Manchester University Press, 1997.

Boghossian P. A. Fear of Knowledge: Against Relativism and Constructivism. Oxford: Oxford University Press, 2006.

Brandom R. Between Saying and Doing: Towards an Analytic Pragmatism. Oxford: Oxford University Press, 2008.

Brandom R. Making It Explicit: Reasoning, Representing, and Discursive Commitment. Cambridge, MA: Harvard University Press, 2001.

Craver C. F. Role Functions, Mechanisms and Hierarchy // Philosophy of Science. 2001. Vol. 68. № 1. P. 53-74.

Deutsch D. Philosophy Will Be the Key That Unlocks Artificial Intelligence // The Guardian. 03.10.2012. URL: http://theguardian.com/science/2012/oct/o3/ philosophy-artificial-intelligence.

Ferrer M. Human Emancipation and "Future Philosophy". Falmouth: Urbanomic, 2015.

Girard J.-Y. Geometry of Interaction VI: A Blueprint for Transcendental Syntax // L'Institut de mathématiques de Luminy. 2013. URL: http://iml.univmrs.fr/ girard/blueprint.pdf.

Laden A.S. Reasoning: A Social Picture. Oxford: Oxford University Press, 2012.

Ladyman J., Lambert J., Wiesner K. What is a Complex System? // European Journal for Philosophy of Science. 2013. Vol. 3. № 1. P. 33-67.

Magnani L. Abductive Cognition: The Epistemological and Ego-cognitive Dimensions of Hypothetical Reasoning. B.: Springer, 2009.

Negarestani R. The Labor of the Inhuman // \#ACCELERATE: The Accelerationist Reader/R. Mackay, A. Avanessian (eds). Falmouth: Urbanomic, 2014. P. $425-466$.

Seibt J. Forms of Emergent Interaction in General Process Theory//Synthese. 2009. Vol. 166. № 3. P. 479-512.

Wilgen W. The Evolution of Human Language: Scenarios, Principles, and Cultural Dynamics. Philadelphia: John Benjamins, 2004.

Wimsatt W. C. Re-Engineering Philosophy for Limited Beings: Piecewise Approximations to Reality. Cambridge, MA: Harvard University Press, 2007.

Woodward J. Making Things Happen: A Theory of Causal Explanation. Oxford: Oxford University Press, 2003. 


\section{THE LABOR OF THE INHUMAN}

Reza Negarestani. Programmer, Critical Philosophy Program, reza.negarestani@ thenewcentre.org.

The New Centre for Research \& Practice, 4739 University Way NE \#1320, WA 98105 Seattle, USA.

Keywords: humanism; inhumanism; inhuman; commitment; space of reasons; revision; human.

The article justifies the project of inhumanism as a practical elaboration of an enlightened humanism. The author consistently distinguishes his inhumanism from anti-humanism, contemporary humanism and so-called kitsch Marxism. Starting from the thesis that the concept of the human is an epistemological one, inhumanism continuously revises what it means to be human. This eradicates what are presumed to be its self-evident characteristics and preserves reliable invariants. Inhumanism is therefore a requirement to engage in construction: it requires that we define what it means to be human and regard it as a constructible and productive hypothesis, as a space for navigation and intervention, while also considering current circumstances. The concept of the human is a commitment to humanity. To make a commitment means asking "What else?" and being attentive to what other commitments it brings forth and to how such derivative commitments demand new modes of action and understanding, new abilities and special acts. Therefore, a stance of construction and revision in relation to the human is necessary in order to understand and commit to humanity, that is, one must begin practicing inhumanism.

The condition for that revision is the autonomy of reason (sapience), which is functionally distinct from sensibility (sentience) in its capacity to engage in discursive practices, to give and ask for reasons. Without such a capacity, being human is merely a biological fact. And this implies an imperative for creating norms rather than only consuming them. Nevertheless, the program for revising reason that inhumanism activates is autonomous: the human does not control it. Inhumanism is the labor of rational agency on the human; hence, one must be a slave to reason in order to be free. Paraphrasing Michel Foucault, the author maintains that every selfportrait of the human is washed away by the revisionary power of reason, each one giving way to more subtle portraits with so few canonical traits remaining that it becomes reasonable whether it makes sense to call what is left "human". This is what functionally distinguishes sapience from sentience.

DOI: $10.22394 / 0869-5377-2021-3-1-36$

\section{References}

Badii R., Politi A. Complexity: Hierarchical Structures and Scaling in Physics, Cambridge, Cambridge University Press, 1999.

Barker H. Arguments for a Theater, Manchester, Manchester University Press, 1997. Boghossian P. A. Fear of Knowledge: Against Relativism and Constructivism, Oxford, Oxford University Press, 2006.

Brandom R. Between Saying and Doing: Towards an Analytic Pragmatism, Oxford, Oxford University Press, 2008.

Brandom R. Making It Explicit: Reasoning, Representing, and Discursive Commitment, Cambridge, MA, Harvard University Press, 2001. 
Craver C. F. Role Functions, Mechanisms and Hierarchy. Philosophy of Science, 2001, vol. 68 , no. 1 , pp. 53-74.

Deutsch D. Philosophy Will Be the Key That Unlocks Artificial Intelligence. The Guardian, October 3, 2012. Available at: http://theguardian.com/science/2012/ oct/o3/philosophy-artificial-intelligence.

Ferrer M. Human Emancipation and "Future Philosophy", Falmouth, Urbanomic, 2015.

Foucault M. Slova i veshchi. Arkheologiia gumanitarnykh nauk [Les mots et les choses. Une archéologie des sciences humaines], Saint Petersburg, A-cad, 1994.

Girard J.-Y. Geometry of Interaction VI: A Blueprint for Transcendental Syntax. L'Institut de mathématiques de Luminy, 2013. Available at: http://iml.univmrs.fr/ girard/blueprint.pdf.

Laden A.S. Reasoning: A Social Picture, Oxford, Oxford University Press, 2012.

Ladyman J., Lambert J., Wiesner K. What is a Complex System? European Journal for Philosophy of Science, 2013, vol. 3, no. 1, pp. 33-67.

Magnani L. Abductive Cognition: The Epistemological and Ego-cognitive Dimensions of Hypothetical Reasoning, Berlin, Springer, 2009.

Negarestani R. The Labor of the Inhuman. \#ACCELERATE: The Accelerationist Reader (eds R. Mackay, A. Avanessian), Falmouth, Urbanomic, 2014, pp. 425466.

Seibt J. Forms of Emergent Interaction in General Process Theory. Synthese, 2009, vol. 166, no. 3, pp. 479-512.

Wilgen W. The Evolution of Human Language: Scenarios, Principles, and Cultural Dynamics, Philadelphia, John Benjamins, 2004.

Wimsatt W. C. Re-Engineering Philosophy for Limited Beings: Piecewise Approximations to Reality, Cambridge, MA, Harvard University Press, 2007.

Wittgenstein L. Filosofskie issledovaniia [Philosophische Untersuchungen]. Filos. rab. Ch. 1 [Philosophical Works. Pt. 1], Moscow, Gnozis, 1994.

Woodward J. Making Things Happen: A Theory of Causal Explanation, Oxford, Oxford University Press, 2003. 